\title{
The Role of International Auditing Standards in Applying Corporate Governance and the Quality of the Professional Performance of the External Auditor
}

\author{
Afrah Alrasheedi*, Ghaith Abualfalayeh" \\ AMMAN University services EST \\ Jordan \\ *Email: Afraah92 [AT] hotmail.com \\ ${ }^{\#}$ Email: gogo5002 [AT] hotmail.com
}

\begin{abstract}
The concept of this particular assignment mainly revolves around the concept of IAS or the International Auditing Standards. Various aspects regarding this context will be analysed in this assignment by considering the auditing and corporate governance standards for the companies of Saudi Arabia. In addition, the effectiveness of IAS in corporate governance and enhancing the quality of the performances standards is also critically described in the assignment. Similarly, if the administration neglects to break down the inner reviewing process, the administrative dangers can stay a way from in the upcoming years. Therefore, the administration will be equipped for producing huge money related advantages every year. This has been distinguished that the International Auditing and Assurance Standard Board sets all the pertinent principles with respect to inspecting exercises in the universal market. For dealing with the review related exercises, the International Auditing and Assurance Standard Board have presented various approaches and procedures.
\end{abstract}

\section{INTRODUCTION}

The international standards of auditing or ISA are a set of professional standards that are used by international companies across the globe to evaluate the financial data. The standards of ISA are mainly is sued by the "International Federation of Accountants" or IFAC as the entire calculation procedure is also based on the Assurance Standard Board or ASB. The ISA is divided into 36 significant standards that also includes sixof the different categories such as "general principals", "Risk as sessment and res ponse", "Audit evidence", "Use of others works", "Conclusion and reporting " and "Specialised areas". On the otherhand, in case of corporate governance, it can be understood that the concept of ISAs can als obe implemented so that the governing operations of a business organisation can be precis ely done. In the modern scen ario, auditing plays a specific role to initiate corporate governance so that the external auditors of the company can successfully establish their audition behaviours. However, applying the IAS standards for enhancing the corporate governance professional capability of the external au ditors of the company can also be enhanced (Chen \& Komal, 2018). The international auditing standards can deliver additional as sistance to the external auditors so that they can analyse the major flaws that are associated with the accounting process of the company. Moreover, corporate governance in the auditing sector of the organisation provides a suitable path for the company so that it can easily achieve the targeted financial objectives.

It can be observed that Saudi Arabia mainly uses the Accounting Standards that is is sued by the Auditing authority of Saudi-Arabia. Moreover, the auditing techniques are issued by the SOCPA or Saudi Organis ation for Certified Public Accountant. The standards is sued by SOCPA of Saudi Arabia are also critically inter-related along with the standards of IAS. The auditing standards of Saudi Arabia als o include the requirement of specific matters that havenot been successfully covered by the standards of IFRS (Torres, Royo \& Garcia-Rayado, 2020). Besides that, the SMEs of Saudi Arabia uses IAS auditing standards so that their accounting reports can be successfully maintained and meas ured especially while initiating the calculations of balance sheets and annual profit and loss account. AS per the SOCPA, while maintaining the auditing reports Saudi companies also published their annual financial reports so that the Individuals can see it on the internet or the company websites. However, as per the rules and legis lation criteria of IAS and SOCPA standards, Saudi Companies are directed to hire the accountant and auditors who have legitimate license and permis sion from the authonity. Moreover, the Accounting and Auditing Organisation for Islamic Financial Institution (AAOIFI) is one of the renewed Islamic non-financial corporate accounting bodies that prepare multiple rules and regulations for doing accounting and auditing operations. On theother hand, the auditing and corporate governance rules that have been incorporated with in the entire financial and economic industry. On the other hand, as per the commercial legis lation license, the financial firms within Saudi Arabia are directed to do the auditing and financial analysis. 


\section{LITERATURE REVIEW}

\subsection{Importance of international auditing standards}

In the international trading process, the companies are forced to consider international auditing standards for avoiding frauds and fin ancial calculation errors in the market. On the other hand, in the opinions of Grant, Harber \& Minter, (2018), if the management fails to analyse the internal au diting process, the managerial risks can be avoided in the upcoming years. As a result, the management will be capable of generating massive financial benefits per year. This has been identified that the International Auditing and Assurance Standard Board sets all the relevant standards regarding auditing activities in the international market. This can be clearly mentioned that with the as sistance of the proper auditing process, the upcoming ris ks can be evaluated and relevant actions to mitig ate the ris ks can be taken into consideration. Therefore, the management will be able to generate massive financial revenue without facing irrelevant managerial risks.

In order to manage the audit related activities, the International Auditing and Assurance Standard Board have introduced numerous policies and processes such as International Audit Quality control, International assurance of audit framework, ISA (International Standards on Auditing) and IAPS (International Auditing Practice Statement). With the help of these policies, the management will be capable of easily maintain a high quality auditing process that can generate massive financial benefit per year. Among all thesestandards, ISA is used in most cases during an international bu siness. ISA can be described as a common audit language in the international market (IAASB, 2020). The audit standard has focused on the basic rules regarding auditing such as evaluation of the financial transaction, reviewing the tran saction with the purchase and sales books, analy sing the calculation format and process, identifying the source of data manipulation and frauds. Based on the features of ISA, international companies can be capable of reducing irrelevant risks regarding auditing in future.

\subsection{Auditing standards of Saudi Arabia}

In Saudi Arabia, this is extremely necessary for the management to implement appropriate auditing analysis per year. In case the management fails to take appropriate au diting features, the financial annual report is not accepted by the in vestors, business partners or other stakeholders. On that basis, the managerial activities will be dis rupted and the management cannot conduct their managerial activities per year. This has been identified based on the Companies Act No. M/6 of 1965, each and every company in Saudi Arabia are forced to implement ISA rules and regulations in a compelling manner (IFAC, 2020). In case the management fails to implement appropriate International Standards on Accounting, the partners and the investors are capable of taking appropriate legalaction ag ainst the business. Therefore, the licence and registration of the company can be cancelled. This is not acceptable for the management as the chances of unnecessary risk can be avoided in the future.

In addition to that, the Public interest entities (PIEs) such as banks are forced to implement IFRS standards. The International Financial Accounting Standard has clearly mentioned that the management needs to review their international transaction in a proper way. In case the management fails to implement the international accounting standards, the capabilities of the organisation will be mitigated in the future years. this is not beneficial for generating mas sive financial benefits. However, according to Inaam \& Khamoussi (2016), in case the management is capable of implementing appropriate rules regarding both IFRS and ISA, the quality of auditing will expand in Saudi Arabia. Therefore, the performance of businesses will improve as the uncertain financial risks will expand in future.

\subsection{Analysing the quality of professional perform ance of external auditors}

In the companies of Saudi Arabia, this is important for the management to hire a high quality, external auditors. This is important for the management to analyse the capabilities of external auditors. Without analysing the capabilities of extemal auditors, the audit analysis of the organis ation will be completely corrupted and the review will not be conduc ted properly. For improving the quality of external auditing, the following steps are needed to be taken into consideration:

i) A proper review of financial transactions: In the Saudi Arabia companies, the management has to focus on evaluating and identifying the needs regarding auditing so that ap propriate management activities can be maintained. In this regards, the external auditors are forced to review all the financial transaction s properly. Along with that, as mentioned by Boskou, Kirkos \& Spathis (2019), this can be identified that with the assistance of proper review of the financial tran sactions, the management capabilities of the companies can be expanded in Saudi Arabia. In addition to that, with the as sistance of proper financial review, the probabilities of fraud and uncertain calculation errors can be reduced in the future. Finally, based on financial reviews, data manipulation can be reduced in the future.

ii) Transparency with the management: Transparency is an extremely important factor in the external auditing process. According to Yuntong \& Xie (2018), in case the management fails to maintain transparency with the management, the quality of the external auditing process will decrease. Along with that, this can be stated that with the assistance of transparency, the actual res ult of the auditing can be described accurately to the management. In cased the external auditors fail to describe the actual result of the auditing process, the financial errors may expand. Nonetheless, transparency in 
external auditing helps the management in detecting the actual source of the is sue. Therefore, the management can be capable of taking effective and sufficient action against it.

iii) Appropriate monitoring and controlling: Appropriate monitoring and controlling process are needed to be considered for avoiding datamanipulation and third party access. As opined by Morris et al. (2019), the external auditors are allowed to analys ethe current team activities. After analysing the team related activities properly, the management will be capable of reducing the calculation related errors and the controlling related risks. On that basis, the management will be capable of generating massive financial benefits as the risks in the calculation can be easily mitigated. Along with that, this can be clearly stated the monitoring and controlling process is beneficial for the management to reduce third party access in the financial information of businesses.

\section{METHODOLOGY}

The methodology regarding audit is regarding its target in the management. The management of Saudi Arabia companies is forced to implement a proper methodology regarding their audit targeting. In case the management neglects the cument methodology reg arding auditing, the managerial risks, hidden cost, underlying assets and future chances of fin ancial risks can be expanded. However, implementing the methodology regarding audit practices can help the management in generating a massive amount of benefits per year. Similarly, the external auditors are needed to be assured about the audit techniques in a proper manner. In case the external auditors are not capable of maintaining appropriate managerial techniques in an appropriate manner, the chances of unnecessary financial risks can be grown. The audit methodology has propersteps which will be discussed briefly in this section.

\subsection{Planning}

Planning is the first step in the methodology of audit analy sis. In this section, a group of audit experts will be forced to take appropriate measures regarding the financial review. With the assistance of the planning process, the activities of the auditor group can be analysed. In a high quality auditing process, one auditor is not enough to complete the entire task without interruption (Derzon et al. 2019). A proper group of experts are developed who are capable of analysing the needs regarding the audit evaluation. In case a proper group of an expert is not selected, the managerial capabilities cannot be able to conduct their activities in a proper manner. Hence, the managerial activities will be corrupted. In addition to that, this can be identified that with the as sistance of planning process, auditing activities such as monitoring, controlling, analysing financial trans actions, comparing data and final submis sion report will be easily developed by the management. On that basis, the chances of unnecessary can be reduced.

\subsection{Risk assessment}

Risk as sessment is a part of the auditing process which helps to analyse the uncertain risks realised due to audit risks. A risk as sessment report is needed to be developed that shows all risks regarding audit are covered. In respect to the ISA auditing rules, risk such as financial, investment, business and marketing risks are recognis ed due to inappropriate auditing. Therefore, this is necessary to develop the risk as sessment report in which the impact of current audit risks will be analysed (Kuitunen-Paul \& Roerecke, 2018). The main activity of the external auditors is to analyse the impact of the audit risks and take appropriate actions so that the managerial risk are identified and mitigated. In case the management fails to take appropriate action regarding the risk management process, a gap in the audit review will be recognised. this gap is not beneficial for the management as their financial ability to generate fin ancial revenue will decrease.

After analysing the impact of the audit risks, the solution for mitigates the negative impact needs to be included by the management. This will helps to reduce the uncertainty and financial errors in the business. As a result, the business will achieve its task within the mentioned deadline. The risk assessment report will also show the reason for the audit risk in the business. Based on the result, the management will take relevant action regarding those employees who caused the audit risk.

3.3 Evaluation of internal controls: The main reas on for audit related risk is ineffective internal control. The management fails to implement appropriate internal control which allows the employees to commit a crime such as fraud and data manipulation (Lewis et al. 2019). For reducing the risks regarding internal control, the external auditors evaluate the cument internal control process of Saudi Arabia companies. The valuation of internal control clearly defines the main is sues that are recognised due to ineffective managerialdecisions. After analysing the gaps in the internal control system, the report is presented to the higher authority. The higher authority evaluates the report and fulfils the gaps by implementing innovative managerial technologies. Based on that, the efficiency of the internal control systemcan be expanded rapidly.

3.4 Audit testing: Audit testing processes are included to measure the efficiency of the auditing process. In case the audit testing processes are not comprehended, then the impact of audit analysis may not be beneficial to the businesses. The auditing process is highly sophisticated as many innovative tools and techniques are implemented in this process (Krishnan et al.2020). Due to the use of data interrogation software, the management is forced to test all results so the bu sinesses can be completely as sured about the authenticity of the result. On that basis, the managerial decision making errors can be 
reduced and financial position can be stabilised properly. Therefore, the businesses will be capable of expanding their bus iness in the international market. As a result, the foreign currency flow of Saudi Arabia may expand.

3.5 Conclusion and reporting: The final factor regarding the auditing process is conclusion and reporting. In this section, audit as sertions are described to the management. Audit assertions can be described as the final result regarding the overall analys is. For each financial transaction in the income statement, balance sheet and cash flow, a significant audit as sertion are presented. The assertion clearly describes if the transaction is right or wrong (Vuolo, Uggen \& Lageson, 2018). Similarly, the audit as sertion will also as sist the management in identifying the risk resolving process. Therefore, suitable action can be taken by thehigher authorities for avoiding managerial is sues.

After presenting all audit assertions, the final conclusion is written. In conclusion, this is clearly described that the management will be able to generate proper financial revenue at the end of the year or not. Along with that, the potential of the employees and chances of external threats will be clearly described in the conclusion (Habib et al. 2019). Finally, what actions will be most suitable and cheap can be described by the management. Based on this calculation process, the management will maintain constant growth.

\section{RESULT}

Audit assertion analy sis is a complex process which cannot be conducted without having a proper knowledge regarding the auditing standards and the analytical process. The management need so hire a skilled and experienced auditor who is capable of analysing the capabilities of the organisation. In case the management is not capable of analysing

\begin{tabular}{|c|c|c|c|}
\hline $\begin{array}{c}\text { Effective Number of } \\
\text { Personnel }\end{array}$ & $\begin{array}{c}\text { Audit Time Stage } \\
\text { 1+Stage 2 (days) }\end{array}$ & $\begin{array}{c}\text { Effective Number of } \\
\text { Personnel }\end{array}$ & $\begin{array}{c}\text { Audit Time Stage } \\
\text { 1+Stage 2 (days) }\end{array}$ \\
\hline $1-5$ & 1.5 & $628-875$ & 12 \\
\hline $6-10$ & 2 & $876-1175$ & 13 \\
\hline $11-15$ & 2.5 & $1176-1550$ & 14 \\
\hline $16-25$ & 3 & $1551-2025$ & 15 \\
\hline $26-45$ & 4 & $2026-2675$ & 16 \\
\hline $45-65$ & 5 & $2676-3450$ & 17 \\
\hline $66-85$ & 6 & $3451-4350$ & 18 \\
\hline $86-125$ & 7 & $4351-5450$ & 19 \\
\hline $126-175$ & 8 & $5451-6800$ & 20 \\
\hline $176-275$ & 9 & $6801-8500$ & 21 \\
\hline $276-425$ & 10 & $8501-10700$ & 22 \\
\hline $426-625$ & 11 & $>10700$ & Follow Progression \\
& & & Above \\
\hline
\end{tabular}

Table 1: Auditanalysis

(Source: Gould et al. 2018)

In respect to the results regarding the current analysis, this can be clearly understood that audit analysis is capable of analysing the progression of fin ancial ability. After analysing the progression of financial ability, the management can be easily capable of analysing the issues in the financial transaction. Similarly, according to Gould et al. (2018), the meas urements regarding the neg ative impact of the audit related ris ks can be identified with the as sistance of this analysis. In case the management is capable of analysing the negative impact regarding the audit risk, then sufficient and suitable tactics for changing the managerial risks can be easily identified. This will reduce the chances of managerial errors .

The above analysis regarding audit evaluation is also clearly showing that the management needs to consider time stage analys is. the time stage analy sis is an important factor for the managerial processes. In case of management is not able to implement relevant time stage analysis, the monitoring and controlling processes will be corrupted (Johnsen et al. 2019). Similarly, this will be recognised that the management will not be able to analyse the capabilities and potential of 
employees. Therefore, the employees will be allowed to commit inappropriate financial calculation and intentional data manipulation. During the international transaction, this type of uncertain and irrelevant data manipulation is not expected by the management. in casethis type of uncertain and ineffective audit risk is realised during the international transaction, a negative market reputation can be realised which is not beneficial for the companies.

The audit process shows that two types of time stage analysis should be implemented in the management. In case two types of time stage calculation are not implemented, the management may notbe capable of conducting appropriate management related activities per year. Similarly, this can be realised that with the assistance of two time stage analysis, errors in the auditing process can be avoided. On that basis, the management will be capable of generating massive financial benefit and conduct their management activities properly (Gunn, Kawada \& Michas, 2019). In the time stage analysis, the number of personnel is analysed and their activities regarding the fin ancial transaction are evaluated. After identifying the most important personnel, suitable monitoring processes are implemented for them. The monitoring process helps in showing the potential of these personneland are they involved in any audit related crime or not.

Similarly, the capabilities of the management can be easily be determined regarding the hiring of staff and internal control system. On that reg ards, the internal risks can be identified by the management (Gallizo Larraz \& Saladrigues Solé, 2016). In some cases, audit analysis helps to analy se the external threats regarding hackers. In the banking sector, hackers try to access personal or business data and manipulate it for increasing business crisis. The audit analysis helps to identify that data manipulation and take proper security measures.

\section{DISCUSSION}

Based on the above result, this can be stated that audit is a significant process that focuses on breaking down the movement of monetary capacity. Subsequent to examining the movement of the money related capacity, the administration can be effectively fit for dissecting the issues in the monetary exchange. Correspondingly, the estimations in regards to the negative effect of the review related dangers can be related to the help of this examination. In the event that the administration is fit for examining the negative effect with respect to the review hazard, at that point adequate and reasonable strategies for changing the administrative dangers can be effectively recognized. This will diminish the probabilities of administrative mis takes in a consistent manner (Stone $e$ t al. 2019). The above investigation with respect to review assessment is equally obviously demonstrating that the adminis tration needs to consider time stage examination. The time stage examination is a significant factor for adminis trative procedures. In the event that the administration cannot actualize pertinent time stage investigation, the checking and controlling procedures will be tainted.

Es sentially, this will perceived that the administration will not have the option to investigate the abilities and capability of workers. In this way, the workers will be permitted to submit un seemly budgetary computation and deliberate information control. During the global exchange, this kind of questionable and unimportant information control is not expected by the administration. In the event that this kind of questionable and insufficient review chance is acknowledged during the world wide exchange, bad market reputation can be acknowledged which is not valuable for the organisations. In this manner, the potential piece of the overall industry will decrease in a consistent way. The review procedure shows that two sorts of time stage examination ought to be actualized in the adminis tration (Samsonova-Taddei\& Siddiqui, 2016). In the event that two types of time stage accounting processes are not executed, the administration may not be fit for leading fitting administration related exercis es every year. Correspondingly, this can be understood that with the help of double cross stage examination, mistakes in the reviewing procedure can be kept away from. On that premise, the adminis tration will be equipped for producing gig antic budgetary advantage and lead their administration exercises appropriately. In the time stage examination, the quantity of faculty is broke down and their exercis es with respect to the money related exchange are as sessed. Subsequent to recognizing the most significant workforce, reasonable observing procedures are executed for them. The checking procedure helps in indicating the capability of this workforce and are they as sociated with any review related wrongdoing ornot.

\section{CONCLUSION}

In respect to the above analysis, this can be stated that organizations are compelled to consider universal examining measures for maintaining a strategic distance from scam and budgetary computation mistakes in the market. Apart from this factor, if the adminis tration neglects to break down the inner reviewing process, the administrative dangers can stay away from in the upcoming years. Therefore, the administration will be equipped for producing huge money related advantages every year. This has been dis tin guished that the International Auditing and Assurance Standard Board sets all the pertinent principles with respect to ins pecting exercises in the universal market. For dealing with the review related exercises, the International Auditing and Assurance Standard Board have presented various approaches and procedures, for example, International Audit Quality control, International confirmation of review structure, ISA and IAPS. W ith the as sis tance of these strategies, the adminis tration will be able to do handily keep up an effective reviewing process that can create gigantic budgetary advantage every year. 
The PIEs, for example, banks are compelled to actualize IFRS principles. The International Financial Accounting Standard has obviously referenced that the adminis tration needs to audit their global exchange in a legitimate manner. In the event that the administration neglects to execute the worldwide accounting measures, the capacities of the as sociation will be moderated later on years. This is not useful for creating gigantic monetary advantages. Be that as it may, in the event that the adminis tration is equipped for actualizing suitable guidelines in regards to both IFRS and ISA, the nature of in specting will grow in Saudi Arabia. For directing the review survey, Transparency is a critical factor in the outside evaluating process. On the off chance that the administration neglects to keep up straightforwardness with the adminis tration, the nature of external evaluating procedure will diminish lateron. Alongside that, this can be expressed that with the help of straightforwardness, the real consequence of the examining can be depicted precis ely to the adminis tration.

\begin{abstract}
Alongside that, arranging is the initial phase in the technique of review investigation. In this segment, a gathering of review specialists will be compelled to take suitable measures with respect to the monetary audit. With the help of arranging process, the exercises of reviewer gathering can be broke down. In an effective examining process, one evaluator is not sufficient to finish the whole as signment without interference. A legitimate gathering of specialists is created who are equipped forbreaking down the requirements in regards to the review assessment. Hazard appraisal is a piece of evaluating process which assists with examining the questionable dan gers acknowledged because of review dangers. A risk evaluation report it should have been built up that shows all dangers with res pect to review are secured. In regard to the ISA in specting rules, hazard, for example, financial, marketing, business and promoting dang ers are perceived due to in proper examining. The above examination concerning survey apprais al is similarly clearly exhibiting that the org anization needs to consider time stage assessment. The time stage assessment is a huge factor for authoritative techniques. If the org anisation cannot realize appropriate time stage examination, the checking and controlling methodology will be spoiled.
\end{abstract}

\title{
7. REFERENCES
}

- Boskou, G., Kirkos, E., \& Spathis, C. (2019). Classifying internal audit quality u sing textual analysis: the case of auditor selection. Managerial Auditing Journal.

- Chen, S., \& Komal, B. (2018). Audit committee fin ancial expertise and earning suality: A meta-analysis. Joumal of Business Research, 84, 253-270.

- Derzon, J., Alford, A., Clarke, N., Gross, I., Shander, A., \& Thurer, R. (2019). Anemia management and audit feedback practices for reducing overuse of RBC transfu sion: a laboratory medicine best practice systematic review and meta-analysis. American journal of clinical pathology, 15l(1), 18-28.

- Gallizo Larraz, J. L., \& Saladrigues Solé, R. (2016). An analysis of determinants of going concern audit opinion: Evidence fromSpain stock exchange. Intangible Capital, 2016, vol. 12, núm. 1, p. 1-16.

- Gould, D. J., Navaïe, D., Purssell, E., Drey, N. S., \& Creedon, S. (2018). Changing the paradigm: messages for hand hygiene education and audit fromcluster analysis. Journal of Hospital Infection, 98(4), 345-351.

- Grant, R., Harber, M., \& Minter, T. (2018). An analysis of the impact of audit firm rotation on au dit fees: a South African perspective. African Journal of Accounting, Auditing and Finance, 6(2), 91-108.

- Gunn, J. L., Kawada, B. S., \& Michas, P. N. (2019). Audit market concentration, audit fees, and audit quality: A cross-country analysis of complex audit clients. Journal of Accounting and Public Policy, 38(6), 106693.

- Habib, A., Bhuiyan, M. B. U., Huang, H. J., \& Miah, M. S. (2019). Determinants of audit report lag: A metaanalys is. International Journal of Auditing, 23(1), 20-44.

- IAASB. (2020). IAASB. Retrieved 18 June 2020, from https://www.iaasb.org/

- IFAC. (2020). Saudi Arabia. Retrieved 18 June 2020, from https://www.ifac.org/aboutifac/membership/country/saudi-

arabia\#: :text=The\%20Companies\%20Act\%20No.,Accountants\%20(CPA)\%20Regulation\%20No.\&text=PIEs $\% 20$ are $\% 20$ required\%20to\%20use, with\%20the\%20Companies\%20Act \%20No.

- Inaam, Z., \& Khamoussi, H. (2016). Audit committee effectiveness, audit quality and earnings management: a meta-analy sis. International Journal of Law and Management.

- Johnsen, Å., Reichborn-Kjennerud, K., Carrington, T., Jeppesen, K. K., Taro, K., \& Vakkuri, J. (2019). Supreme audit institutions in a high-impact context: A comparative analysis of performance audit in four Nordic countries. Financial Accountability \& Management, 35(2), 158-181.

- Krishnan, A., Justus, S., Raj, A., Jaison, J., Shaji, N. S., Unnimaya, V. S., ... \& Sriram, A. (2020). Energy Audit: A Case Study in a Rubberwood Processing Industry. In Advances in Electric Power and Energy Infrastructure (pp. 239-249). Springer, Singapore.

- Kuitunen-Paul, S., \& Roerecke, M. (2018). Alcohol Use Disorders Identification Test (AUDIT) and mortality risk: a sys tematic review and meta-analysis. J Epidemiol Community Health, 72(9), 856-863.

- Lewis, T., Kennedy, J., Price, G., Mee, T., Woolf, D., Bayman, N., ... \& Hudson, A. (2019). Palliative lung radiotherapy at the Christie: audit of prescribing practice and survival analysis. Lung Cancer, 127, S81-S82. 
- Morris, S., Ramsay, A.I., Boaden, R. J., Hunter, R. M., McKevitt, C., Paley, L., ... \& Wolfe, C. D. (2019). Impact and sustainability of centralising acute stroke services in English metropolitan areas: retrospective analysis of hospital epis ode statis tics and stroke national audit data. $b m j, 364,11$.

- Sams onova-Taddei, A., \& Siddiqui, J. (2016). Regulation and the promotion of audit ethics: Analysis of the content of the EU's policy. Journal of Business Ethics, 139(1), 183-195.

- Stone, P., Baxter, N., McMillan, V., Roberts, C. M., Quint, J. K., \& Singh, S. J. (2019). What Influences Referral to Pulmonary Rehabilitation from Primary Care: Analysis of National Audit Data. In C106. PULMONARY REHABILITATION (pp. A5738-A5738). American Thoracic Society.

- Torres, L., Royo, S., \& Garcia-Rayado, J. (2020). Social media adoption by Audit Institutions. A comparative analys is of Europe and the United States. Government Information Quarterly, 37(1), 101433.

- Vuolo, M., Uggen, C., \& Lageson, S. (2018). To match or not to match? Statis tical and substantive considerations in audit design and analysis. In Audit studies: Behind the scenes with theory, method, and nuance (pp. 119-140). Springer, Cham.

- Yuntong, H. U., \& Xie, B. (2018). Internal audit of university affiliated hospitals: status quo and problems analys is. Chinese Journal of Hospital Administration, 34(3), 252-255. 